\title{
Cost-utility analysis of a consensus and evidence-based medication review to optimize and potentially reduce psychotropic drug prescription in institutionalized dementia patients
}

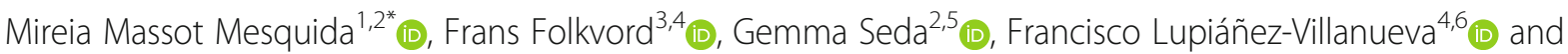 \\ Pere Torán Monserrat ${ }^{2,5}$ (I)
}

\begin{abstract}
Background: Growing evidence shows the effects of psychotropic drugs on the evolution of dementia. Until now, only a few studies have evaluated the cost-effectiveness of psychotropic drugs in institutionalized dementia patients. This study aims to assess the cost-utility of intervention performed in the metropolitan area of Barcelona (Spain) (MN) based on consensus between specialized caregivers involved in the management of dementia patients for optimizing and potentially reducing the prescription of inappropriate psychotropic drugs in this population. This analysis was conducted using the Monitoring and Assessment Framework for the European Innovation Partnership on Active and Healthy Ageing (MAFEIP) tool.
\end{abstract}

Methods: The MAFEIP tool builds up from a variety of surrogate endpoints commonly used across different studies in order to estimate health and economic outcomes in terms of incremental changes in quality adjusted life years (QALYS), as well as health and social care utilization. Cost estimates are based on scientific literature and expert opinion; they are direct costs and include medical visits, hospital care, medical tests and exams and drugs administered, among other concepts. The healthcare costs of patients using the intervention were calculated by means of a medication review that compared patients' drug-related costs before, during and after the use of the intervention conducted in MN between 2012 and 2014. The cost-utility analysis was performed from the perspective of a health care system with a time horizon of 12 months.

Results: The tool calculated the incremental cost-effectiveness ratio (ICER) of the intervention, revealing it to be dominant, or rather, better (more effective) and cheaper than the current (standard) care. The ICER of the intervention was in the lower right quadrant, making it an intervention that is always accepted even with the lowest given Willingness to Pay (WTP) threshold value $(€ 15,000)$.

\footnotetext{
* Correspondence: mmassot.mn.ics@gencat.cat

'Servei d'Atenció Primària Vallès Occidental, Direcció d'Atenció Primària Metropolitana Nord. Institut Català de la Salut. Sabadell, Barcelona, Spain ${ }^{2}$ Grup de Recerca Multidisciplinar en Salut i Societat (GREMSAS), accredited by AGAUR (2017 SGR 917), Barcelona, Spain

Full list of author information is available at the end of the article
}

C C The Author(s). 2021 Open Access This article is licensed under a Creative Commons Attribution 4.0 International License, which permits use, sharing, adaptation, distribution and reproduction in any medium or format, as long as you give appropriate credit to the original author(s) and the source, provide a link to the Creative Commons licence, and indicate if changes were made. The images or other third party material in this article are included in the article's Creative Commons licence, unless indicated otherwise in a credit line to the material. If material is not included in the article's Creative Commons licence and your intended use is not permitted by statutory regulation or exceeds the permitted use, you will need to obtain permission directly from the copyright holder. To view a copy of this licence, visit http://creativecommons.org/licenses/by/4.0/. The Creative Commons Public Domain Dedication waiver (http://creativecommons.org/publicdomain/zero/1.0/) applies to the data made available in this article, unless otherwise stated in a credit line to the data. 
Conclusions: The results of this study show that the intervention was dominant, or rather, better (more effective) and cheaper than the current (standard) care. This dominant intervention is therefore recommended to interested investors for systematic application.

Keywords: Cost-benefit analysis, Patient-centered medication review, Dementia, Psychotropic drugs, Nursing homes, Institutionalized patients

\section{Background}

Patients with dementia often present neuropsychiatric symptoms. These are known as behavioral and psychological symptoms of dementia (BPSD) and are a common motive for medical consultations, hospital admissions, and nursing home stays [1]. It is estimated that at least $90 \%$ of dementia patients will develop some type of BPSD over a period of 5 years.

Several studies [2, 3] have cautioned about the risks of treating BPSD with psychotropic drugs. Psychotropic drug use has been associated with decreased cognitive capacity, rigidity, and somnolence and may result in complications such as pneumonia [4], increased risk of experiencing dementia (around 50\%) [5] and mortality $[2,6]$ in institutionalized dementia patients. These negative consequences suggest that interventions aimed at reducing the risks associated with these drugs might be necessary.

Psychotropic drugs are not the only cause for concern in institutionalized dementia patients; polypharmacy itself is another important factor that must be taken into account to prevent adverse events and potentially inappropriate prescriptions in this population [7].

Numerous studies have demonstrated the effectiveness of medication reviews conducted either by a pharmacist alone or a multidisciplinary team in reducing inappropriate medication [8-10] and its impact [11, 12], either in terms of cost reduction [13] and increased quality of life [12, 14], although not always with favorable results [15-17].

While several studies have demonstrated the effectiveness of interventions aimed at reducing the use of psychotropic drugs in institutionalized dementia patients [18-21], few have evaluated their cost-effectiveness or the impact of these interventions on patients' quality of life [22]. Additionally, despite showing a reduction in the consumption of psychotropic drugs, no clear benefit has been proven (or the results are contradictory). One potential explanation for this is that these studies evaluated different types of interventions and, therefore, the results will necessarily differ. Another possibility is that they evaluated the cost-utility of a combination of interventions that, in addition to a medication review, included behavioral support intervention. For example, in a study by Ballard et al. [23], patient-centered intervention resulted in increased quality of life even though there was no significant reduction in the consumption of psychotropic drugs in either the intervention or control group. These outcomes are aligned with a 2017 study by Ballard et al. [24] in which social interaction intervention was reported as the only type of intervention that led to increased quality of life. The cost-analysis of the intervention revealed a significant reduction in social and healthcare costs in the intervention group as compared with the control group.

Richter et al. [25], on the other hand, did not analyze cost-effectiveness in their study because the results of the control group were better than those of the intervention group. Harrison et al. found that greater exposure to psychotropic drugs is linked to lower quality of life [26] in contrast with the findings of Ballard et al. [24], in which the reduced use of psychotropic drugs in dementia patients worsened quality of life. However, in another study, Ballard et al. [27] concluded that the discontinuation of antipsychotics may have little or no effect on overall cognitive function. Discontinuation may make no difference to adverse events or quality of life. In a 2016 study, Ballard et al. [28] used mortality analysis to review psychotropic drugs linked to social intervention and identified a reduction in mortality as compared to receiving no intervention.

This study aims to assess the cost-effectiveness of an intervention based on consensus between the primary care pharmacists, GPs and nursing home physicians and nurses involved in the management of dementia patients for optimizing and potentially reducing the prescription of inappropriate psychotropic drugs in this population. The analysis was conducted using the Monitoring and Assessment Framework for the European Innovation Partnership on Active and Healthy Ageing (MAFEIP) tool $[29,30]$.

\section{Methods}

\section{Intervention analyzed}

The details of the actual intervention analyzed in this study are described elsewhere [31]. In short, the analyzed intervention was performed in the metropolitan area of Barcelona Catalonia (Spain) (MN) between 2012 and 2014. The patients included were institutionalized dementia patients with pharmacological treatment with one or more psychotropic drugs from the Anatomical Therapeutic Chemical Classification System (ATC) code $\mathrm{N}$ of the World Health Organization (WHO) [32] for 3 
months or longer. It was a structured, patient-centered medication review by a multidisciplinary team (primary care pharmacists, GPs, nursing home physicians and nurses) aimed at reducing inappropriate psychotropic drug prescriptions based on a therapeutic guideline for treating BPSD (created by a multidisciplinary team) as compared to standard care. Before implementing the medication review, one general practitioner (GP) and one primary care pharmacist underwent a training phase focused on managing patients with BPSD. Then, before each scheduled visit with the nursing home physician and nurse, the medication the patient was receiving was evaluated by the GP and pharmacist to detect any incidents related to the prescription (e.g., duplicates, inappropriate drugs) and to determine which prescription-related aspects required evaluation of the patient for decisionmaking (continue or discontinue a drug). As for the working session in the nursing home, before conducting the medication review (of all drugs included in the therapeutic plan), the GP and pharmacist met with the nursing home physician and nurse to establish the patient's current status with regard to his/her prognosis, level of dependence, and frailty. This was done to facilitate decisions on the need to adapt the intensity of treatment, change treatment, or discontinue treatment based on the risk-benefit ratio for the patient. Patient assessment included the severity of dementia (Global Dementia Scale [GDS]), level of dependence (Barthel index score), cognitive state (Pfeiffer test), and prognosis (in end-of-life patients). Treatment assessment included the indication, effectiveness, and safety (duplicates, interactions, contraindications) of the drugs prescribed. Based on these evaluations, changes in the patient's treatment plan considered to be appropriate and relevant were proposed. Follow-up of the consensus changes was carried out at 1 and 6 months to determine whether any psychotropic drugs that had been discontinued after the interview should be restarted, the dosage of drugs that had been reduced should be increased, or a new psychotropic drug should be initiated. Over the course of the intervention, the mean number of drugs prescribed per patient decreased from 8.04 at baseline to 5.86 at 6 months and from 2.71 to 2.01 for psychotropic drugs.

\section{Model description}

The analysis was conducted using the Monitoring and Assessment Framework for the European Innovation Partnership on Active and Healthy Ageing (MAFEIP) tool. In MAFEIP Users Guide Manual [33] describes the basic principles of the tool to better understand the tool and how it works. In this manual is described the MAFEIP tool is founded on the principles of Decision Analytic Modelling (DAM), an approach commonly used to evaluate the health and economic impact of healthcare innovations. More precisely, MAFEIP is based, by default, on a generic three-state Markov model, which provides the flexibility required to be adaptable to a large number of studies that focus on a variety of objectives, implement different interventions and target different cohorts of individuals with different demographic or disease characteristics.

\section{Transition states}

The outcomes for the intervention and control group are calculated by simulating the health status of the target population as it transitions through the three health states defined in the Markov model: baseline health, deteriorated health, and dead (Fig. 1). Each health state is defined by an amount of resource use and quality of life (utility). This represents the average resource use and quality of life of a patient in that health state.

In the simulation, the population moves through the Markov states based on four transition probabilities: 1) Transition from the baseline health state to the deteriorated health state represents a patient becoming ill (i.e., the incidence of the deteriorated health condition); 2) Patients move from the deteriorated health state to the baseline health state when their illness is cured (i.e., the rate of recovery back to baseline health); 3 ) Transition to the dead state from the baseline state (i.e., baseline mortality in the target population); 4) Transition to the dead state from the deteriorated health state (i.e., excess mortality in the population with deteriorated health).

The MAFEIP tool builds up from a variety of surrogate endpoints commonly used across different studies in order to estimate health and economic outcomes in terms of incremental changes in quality adjusted life years (QALYs), as well as health and social care utilization.

\section{Three state Markov model}

A highly adaptable Markov model with initially three mutually exclusive health states (baseline health, deteriorated health and death) forms the basis of the tool, which draws from an extensive database of epidemiological, economic and effectiveness data. It also allows for further customization through remote data entry, thus enabling more accurate and context-specific estimation of intervention impact.

In our study, the three-state Markov model of the MAFEIP tool was used to describe patients without dementia (baseline health state), patients with dementia (deteriorated health state), and death. Nonetheless, considering there were no patients without dementia, and the probability that patients with dementia would improve and go to the baseline health state was zero. In the MAFEIP-tool it is not possible to dismiss this state. The study combined data from nursing homes with data collected from external sources to populate the model 


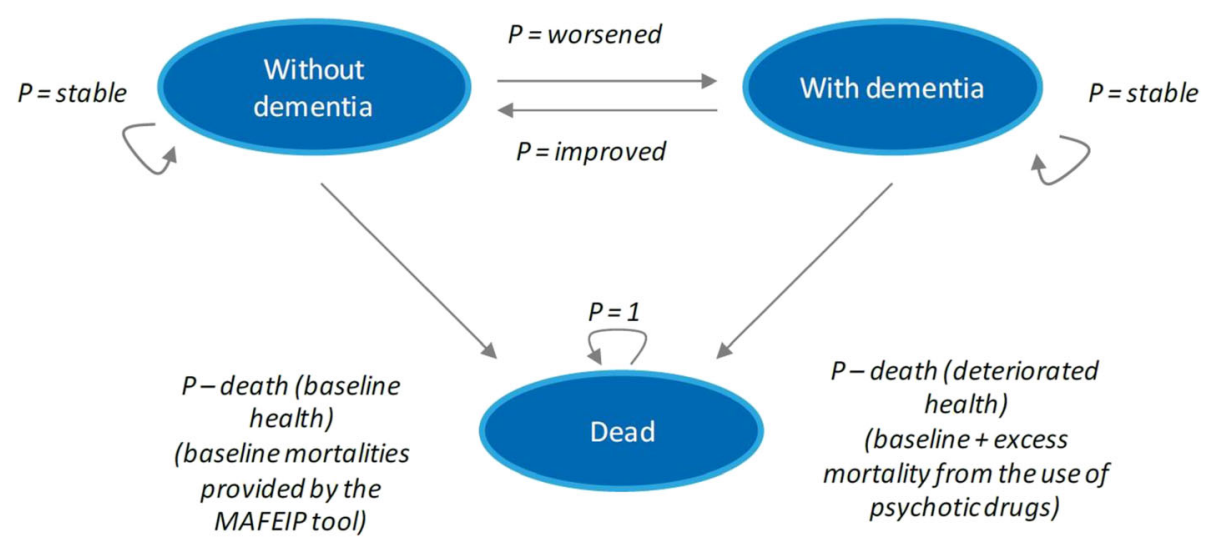

Fig. 1 Three-state Markov model used in MAFEIP tool

with values for transition probabilities and relative risk of mortality. Incidence rates were derived from data on the prevalence of dementia in institutionalized patients in our reference area. Moreover, estimates on mortality rates were derived from the findings of the DART-AD [2] clinical trial, which reported higher survival rates in patients who were given placebo drugs instead of neuroleptics.

\section{Costs and utility values}

Cost estimates were based on scientific literature, the eSalud database [34] and expert opinion. The cost estimates are direct costs, including medical visits, hospital care, medical tests and exams and drugs administered, among other concepts.

The healthcare costs of patients using the intervention were calculated by means of a medication review that compared drug-related costs of the patients before, during, and after the use of the intervention.

Intervention cost estimates were based on the amount of time spent by the physician, pharmacist, and/or nurse with the patients.

Regarding utility values, the study did not focus on utility calculations but used secondary sources to provide general and averaged estimates [35]. Utility values of the baseline group describe data collected on health-related quality of life (HR-QoL) [36] for people from the same country and of the same age group who do not have dementia. Since the intervention has been shown to have an impact on mortality rates rather than HR-QoL, utility values for the control group and intervention group are similar. (Utility for control and intervention group: baseline 0.70 and deteriorated 0.27 ).

The cost-utility analysis was performed from the perspective of a health care system with a time horizon of 12 months. It was focused on calculating the incremental cost-effectiveness ratio (ICER) of the intervention and comparing it to the standard of care. In addition to the analyses on the outcomes; we have included the willingness to pay as a threshold to show the relation between this willingness to pay and the cost-effectiveness of the outcomes.

\section{Model and base case}

As previously mentioned, the use case takes into account the three-state Markov model depicted in Fig. 1.

Each health state describes institutionalized patients between 65 and 90 years of age. The baseline health state describes patients without dementia whereas the deteriorated health state describes patients with dementia. Records show that the prevalence of dementia in institutionalized patients in our reference area is $40 \%$. This is adopted as the incidence rate for both the preintervention group and postintervention group since the intervention does not focus on reducing the rate of incidence of dementia and therefore does not affect it. In this use case, it was assumed that patients cannot completely recover once they already have dementia and, thus, recovery rates were set to 0 for both groups. (Transition probabilities: intervention and control group, incidence rate: 40 and recovery rate: 0 ).

Mortality rate estimates were derived from the findings of the DART-AD [2] clinical trial, which reported higher survival rates in patients who were given placebo drugs instead of neuroleptics. Based on the clinical trial, the cumulative probability of survival at 12 months was $70 \%$ in the preinetrvention group (those who continued treatment with neuroleptics) vs. $77 \%$ in the postintervention group (those who withdrew neuroleptics). Moreover, the results show that the difference between the groups was greater after longer periods: at 24 months, survival rate was $46 \%$ vs. $71 \%$ and at 36 months, it was $30 \%$ vs. $59 \%$. The mortality rates were obtained by first calculating the mean of all the survival rates given $(49 \%$ 
vs. $69 \%$ or 0.49 vs. 0.69 ) and then subtracting the mean survival rates from 1 . (Calculated mortality rate: 0.51 vs. $0.31)$.

\section{Relative risk of mortality}

The MAFEIP tool uses another measure for estimating mortality in a given population: the relative risk of mortality (RR). This is calculated by dividing the mortality rates in the use case by the mortality for a reference condition. In this particular use case, the reference condition is the age-dependent, all-cause mortality of the Spanish population as recorded in the Human Mortality Database (https://www.mortality.org/). The RR values were a baseline health of 1 and deteriorated health of 1.31 for the postintervention group, and 1 and 1.51 for the preintervention group, respectively.

Patients in the baseline health state had an RR of 1 . This is the default value and it prompts the tool to simply use data that is stored in the Human Mortality Database. Those in the deteriorated health state, however, were given an $R R$ greater than 1 . Choosing the value $R R>1$ leads the tool to interpret this as excess mortality to be added to the existing data from the Human Mortality Database (i.e., mortality rate from database + excess mortality from use of neuroleptics).

Across all patient groups, those who had dementia (deteriorated state) and were given neuroleptics (preinetrvention group) had the highest mortality rate (1.51 is higher than baseline and higher than the postintervention group). Mean patient age was 87.09 years (SD: $6.795)$, and $75 \%(n=180)$ were women. There were no significant differences in patient age between the participating nursing homes.

\section{Computing the costs}

The drug-costs were calculated considering the drug prescribed, dose and frequency for then calculate the number of boxes according to the length of treatment or if the length was more than a year it was considered a maximum length of 1 year period time. This was calculated for each drug from patient pharmacotherapy. The final cost was the sum of the number of boxes multiplied by its cost.

Intervention cost estimates were based on the amount of time spent by the physician, pharmacist, and/or nurse with the patients. The total sum of intervention costs calculated from the staff spending $30 \mathrm{~min}$ with each patient, in accordance with the therapeutic plan, came to $€ 11,654.40$ or $€ 48.56$ per patient. Since the patient does not have to pay for the therapeutic guide itself before it is used, the intervention one-off costs were left at 0 .

Cost estimates described the average healthcare costs per dementia patient per year as ranging from approximately $€ 3596.88$ to $€ 5130.90$, adapted from social- economic studies of Alzheimer disease and vascular dementia patients based in Spain [35, 37].

However, for this use case, the intervention specifically aimed to reduce the amount of neuroleptic drugs given to patients. A study of the costs of this intervention included a medication review that compared drug-related costs of the patients before, during, and after the use of the intervention. For this reason, only drug-related costs were considered in the MAFEIP tool.

Drug-related costs per patient were calculated to be $€ 2265.68$ before the intervention, $€ 1720.77$ at 1 month after intervention and $€ 1539.90$ at 6 months after the intervention. All other costs were considered constants. The Table 1 summarizes the results of the medication review and the rest of model parameters. These are transferred to the MAFEIP tool as follows:

\section{Results}

We will present the results by showing the incremental costs planes, which show the difference between the cost that a person with a specific age and gender would have if this person received the intervention minus the cost that would have occurred if this person followed current care. In addition, the incremental effects values show how much quality of life is gained when the intervention is used instead of standard care, comparing them by age-gender group. Next, the ICER will be presented, which is the incremental cost-effectiveness ratio. This is presented as a blue dot and shows whether the intervention is not acceptable (more costly and/or less effective) or acceptable (less costly and/or more effective). The incremental costs by age all fall below zero (negative), as shown in Fig. 2. Negative incremental cost can be interpreted as "savings" that the intervention may generate, whereas positive results can be interpreted as additional costs required by the intervention as compared to standard care. The figure below shows that the incremental costs by age are all negative, which implies that the intervention (having a therapeutic guideline and plan) is cheaper than standard care (continuing with neuroleptic prescriptions only). The graph below also shows that the costs remain negative across the age range (65 to 90 years), although they do increase as age increases (depicted by upward curve).

The graph portraying incremental effects by age (Fig. 3) shows how many QALYs each age group in the target group was able to benefit from if the intervention was used. Since this use case did not focus on impact on QALYs, the values in the graph remain close to the earlier input value ( 0.7 baseline and 0.27 deteriorated state). The graph also illustrates that QALYs are lower at an older age.

Figures 4 and 5 presents an extension of the previous results by showing the population-level impact on costs 
Table 1 Summary table of model parameters included

Demographic characteristics of target group
Geographic characteristics of target group
Target population minimum age
Target population maximum age
Incidence rate of dementia in institutionalized patients in our area
Recovery rate
Relative Risk of Mortality in baseline health
Relative Risk of Mortality in dementia patients ${ }^{b}$
Intervention one-off costs (per patient)
Intervention recurrent costs (per patient and year)
Healthcare costs baseline health
Healthcare costs dementia patients
Utility

Mean age
Sex
Country
Region
65
90

Before Intervention

$40 \%$

$0 \%{ }^{\mathrm{a}}$

1

1.51

0

$2266 €$

0.70

87.09 (SD 6.675)
$75 \%$ women
Spain

Catalonia

After intervention

$40 \%$

$0 \%{ }^{\mathrm{a}}$

1

1.31

0

$48.56 €$

0

$1630 €$

0.27

${ }^{\mathrm{a}}$ Recovery rate was considered $0 \%$ because once a patient is diagnosed with dementia there is no recovery. ${ }^{\mathrm{b}}$ Estimates on mortality rates were derived from the findings of the DART-AD [2] clinical trial. Baseline health costs were left at 0 since the intervention only focuses on patients that are already in a deteriorated health state (they already have dementia). The healthcare cost deteriorated health after intervention were calculated as the drug-related costs mean per patient recorded at 1 and 6 months after the intervention

and effects over a period of time (40 years). A sample population of 200 was chosen.

The ICER takes into account both the potential incremental costs and incremental effects that intervention may provide. In this example, the ICER is described as "dominant" and its exact value (represented by the blue dot in Fig. 6) is located in the lower-right quadrant of the graph. If an intervention is "dominant" it means that it is better (more effective) and cheaper than the current (standard) care. It also means that the intervention is (always) accepted and, therefore, possibly of value to interested investors.

Moreover, the WTP threshold describes the maximum amount patients are willing to pay given a certain QALY. In our study we have used 15k/QALY as he WTP threshold. When the ICER is less than the WTP, it means that the intervention is cheaper than what patients are willing to pay for it (also making the intervention accepted).

Figures 7 and 8 reflect the simulation results based on the transition probabilities described earlier. The graphs

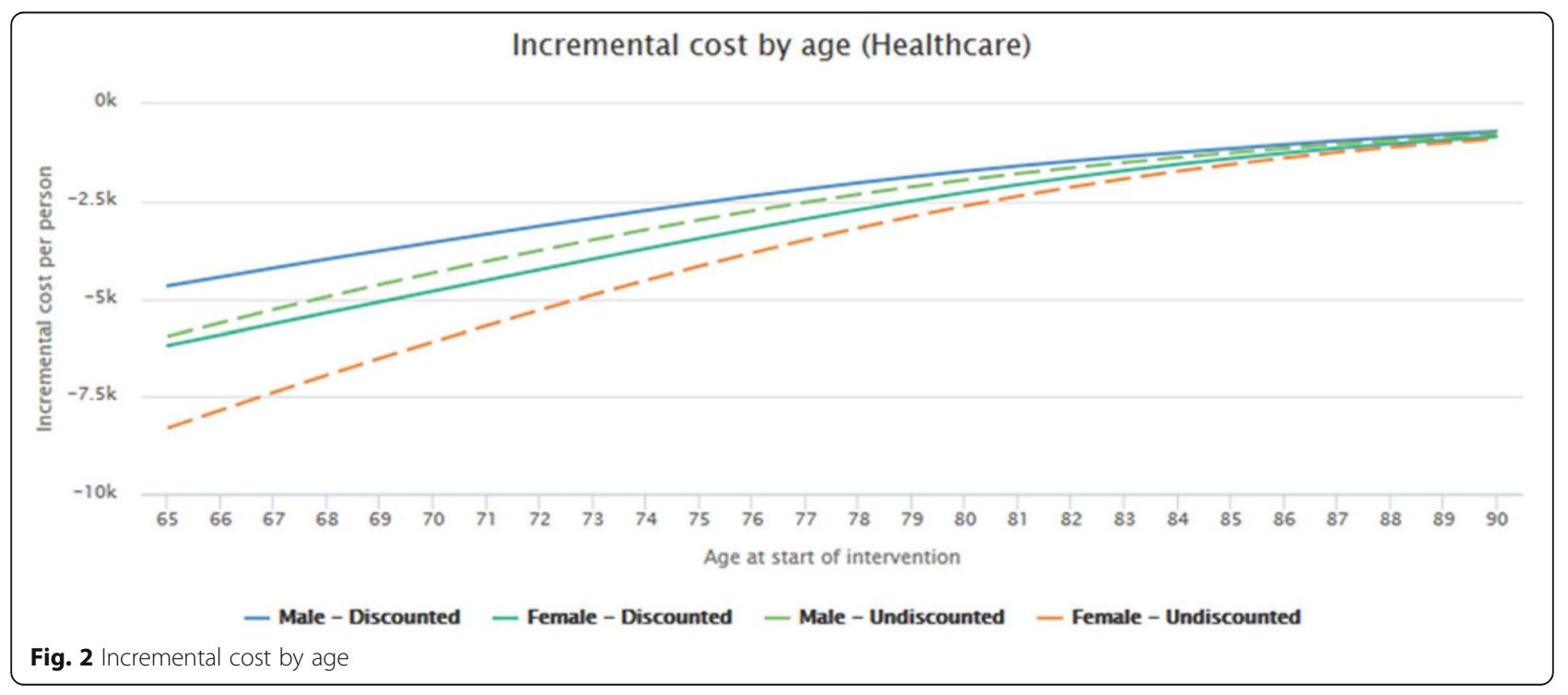




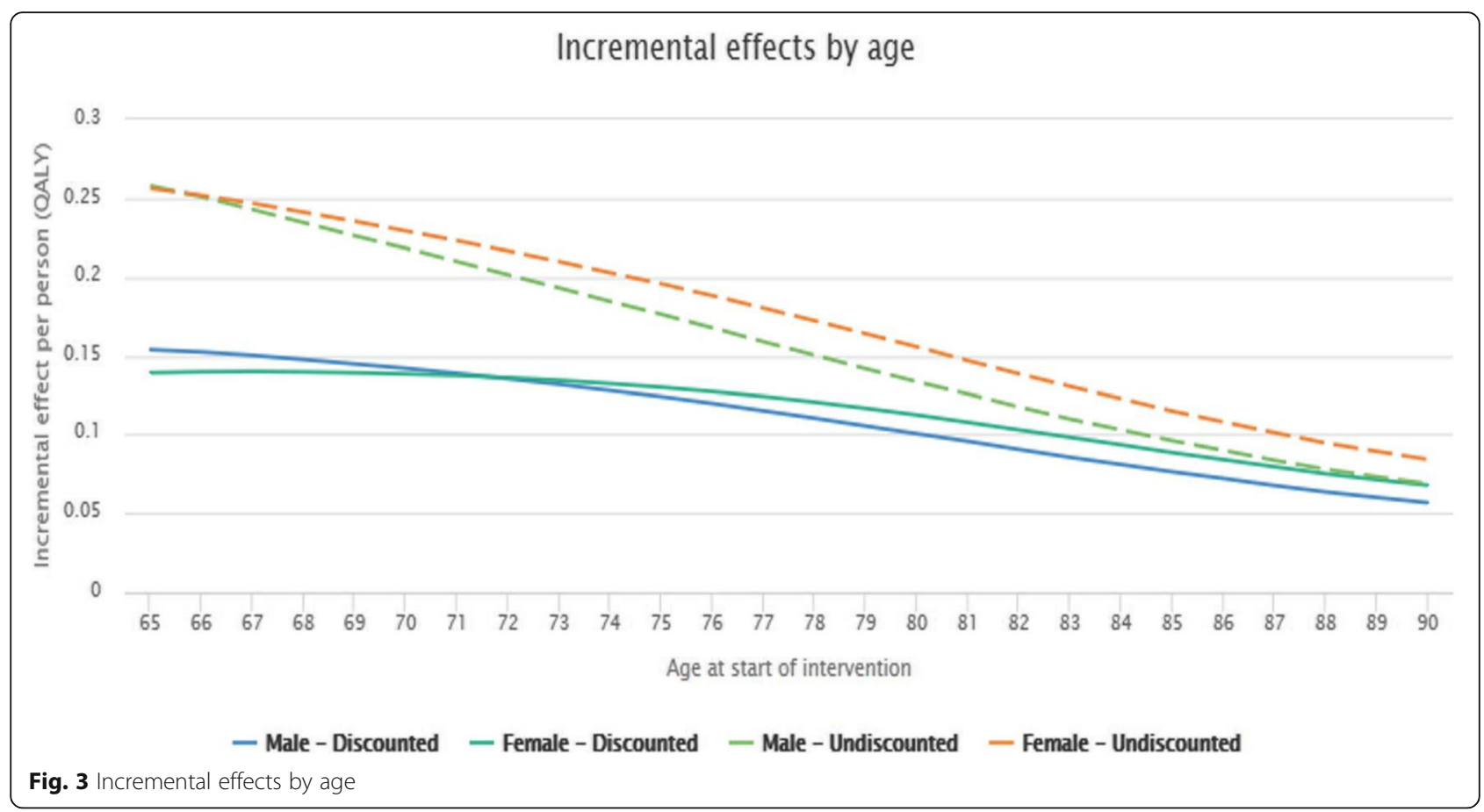

illustrate how likely it is that a patient from a given age group and health state will remain in an alive state or move to the dead state. Mortality rates of patients without dementia (baseline health state) were set to the default value of 1 . The tool then took ageand country-dependent, all-cause mortality rates from the Human Mortality Database.
In order to better compare the effect of the intervention (therapeutic plan) vs. current care (neuroleptics) specifically for patients in the deteriorated state (with dementia), the plots depicting the baseline health states were deselected (Fig. 8). The graph shows that there are better chances of remaining in an alive state when using the intervention rather than current care.

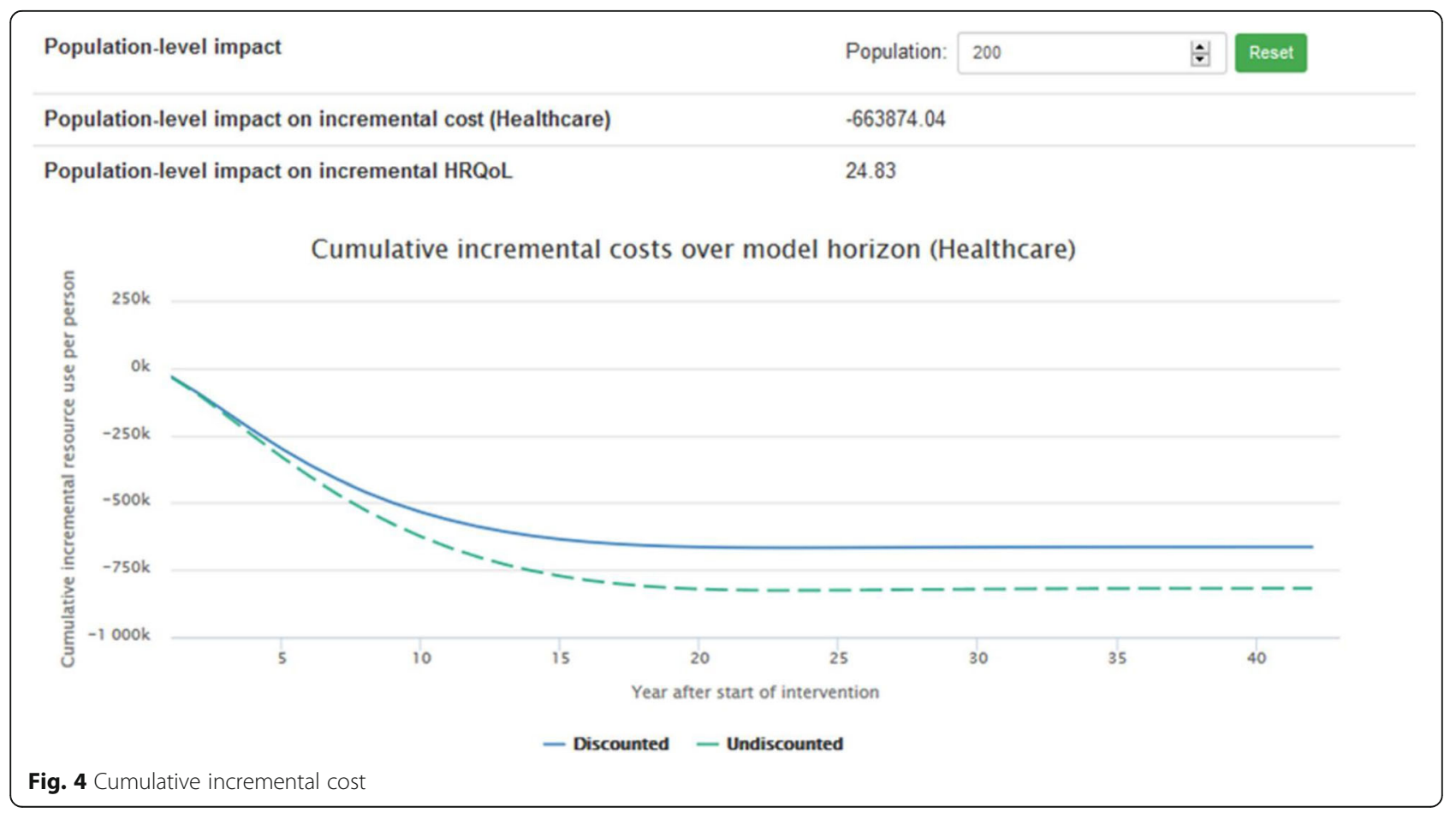




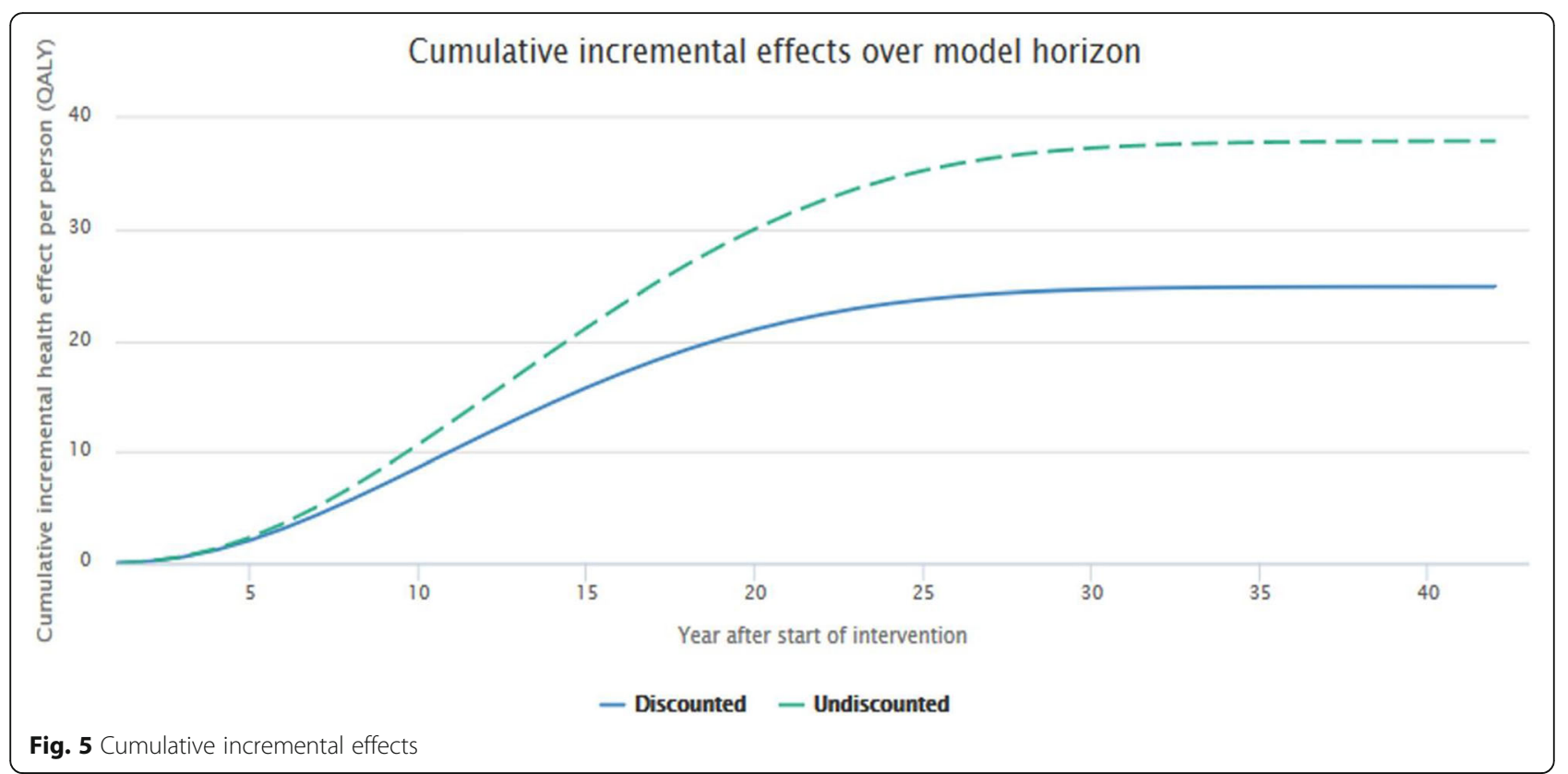

Figure 9 describes the probability of patients moving to the dead state (by age group). The graph illustrates how patients using the intervention have lower chances of dying when compared to patients still being given neuroleptics (current care).

\section{Discussion}

This study aims to assess the cost-effectiveness of an intervention based on consensus between the primary care pharmacists, GPs and nursing home physicians and nurses involved in the management of dementia patients for optimizing and potentially reducing the prescription of inappropriate psychotropic drugs in this population. Intervention based on specific, evidence-based therapeutic guidelines designed by a multidisciplinary team and implemented through consensus together with a patient-centered clinical medication review has proven to be a dominant or cost-effective intervention. This

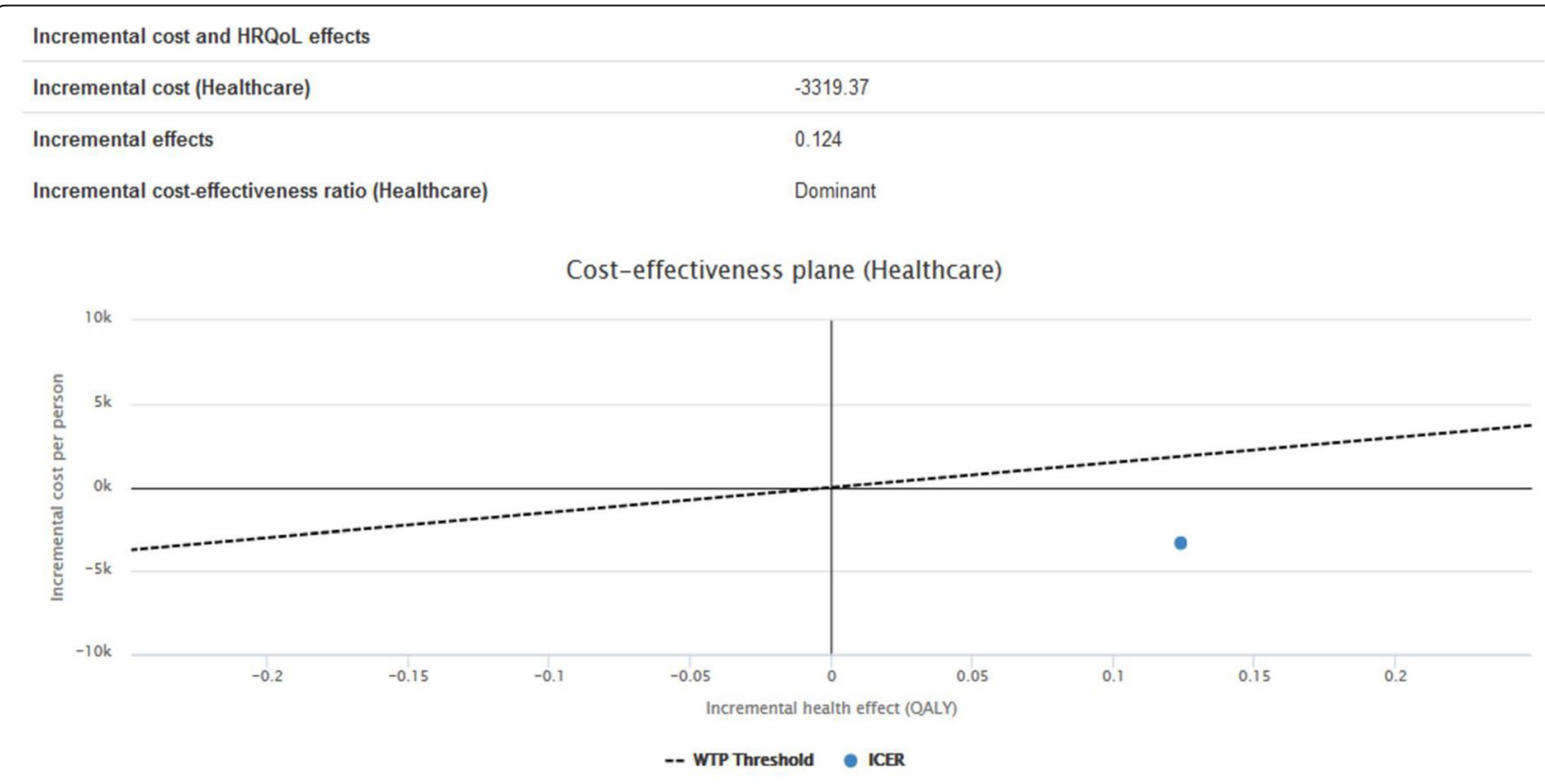

WTP Threshold: $\bigcirc € 15 K / Q A L Y \bigcirc € 20 K / Q A L Y \bigcirc € 30 K / Q A L Y \bigcirc € 50 K / Q A L Y \bigcirc € 80 K / Q A L Y$

Fig. 6 Cost-effectiveness plane 


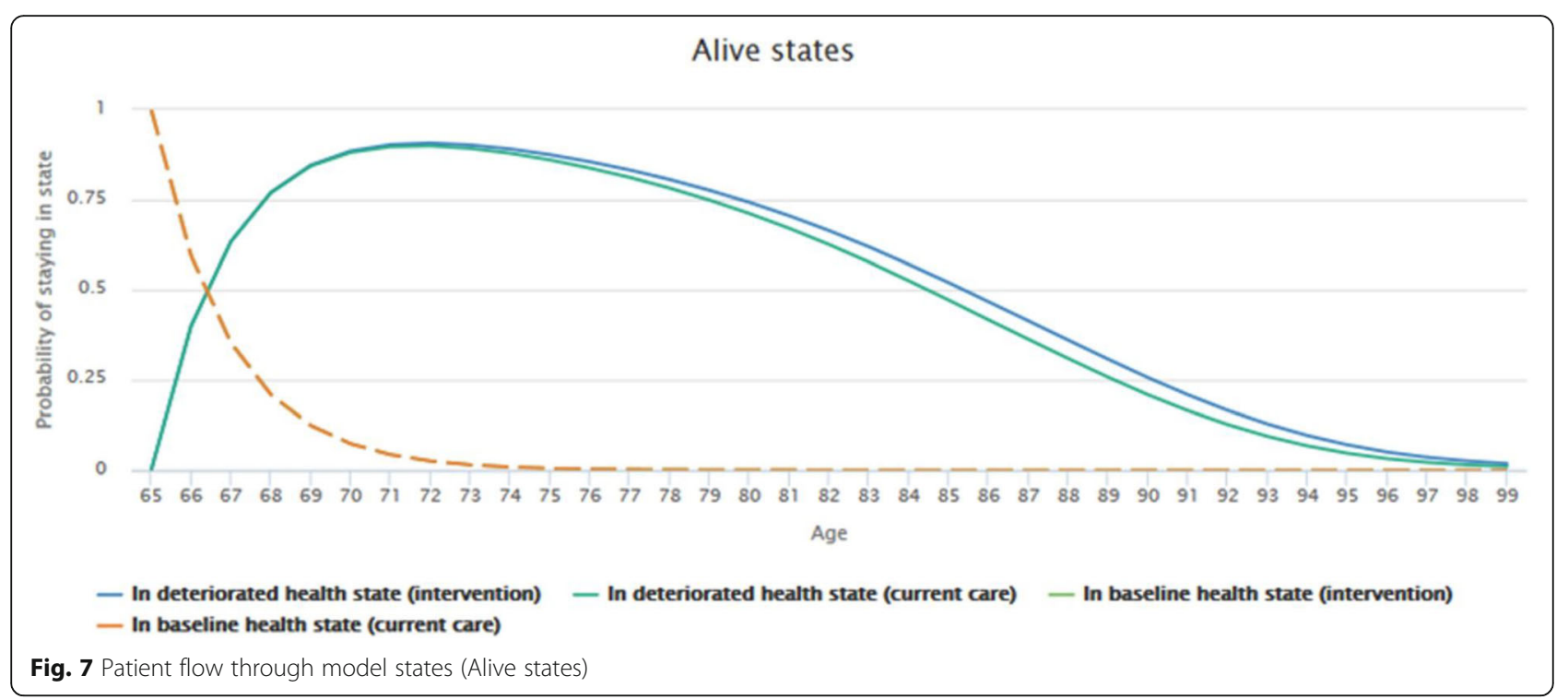

means that the intervention is better (more effective) and cheaper than the current (standard) care. The results describe an intervention that is always recommended to be accepted, even with the lowest given WTP threshold value $(€ 15,000)$.

The positive results obtained in this cost-utility analysis are due to the number of drugs and psychotropic drugs deprescribed and, based on the evidence [2], their impact on mortality outcomes in institutionalized dementia patients. The mean number of drugs prescribed per patient decreased from 8.04 at baseline to 5.86 at 6 months and from 2.71 to 2.01 for psychotropic drugs.
This reduction could be due to the methodology used: patient-centered clinical medication review by a multidisciplinary team, decision-making based on a single guide used by all team members, and the solving of different issues through an on-site meeting with all the managers responsible for patient care, in which the therapeutic objectives were shared, thus favoring joint decision making. A systematic review by Kwak et al. [17] that analyzed all the economic studies on medication review interventions conducted by pharmacists in nursing homes did not obtain a clear conclusion due to the heterogeneity of the studies included. In the discussion,

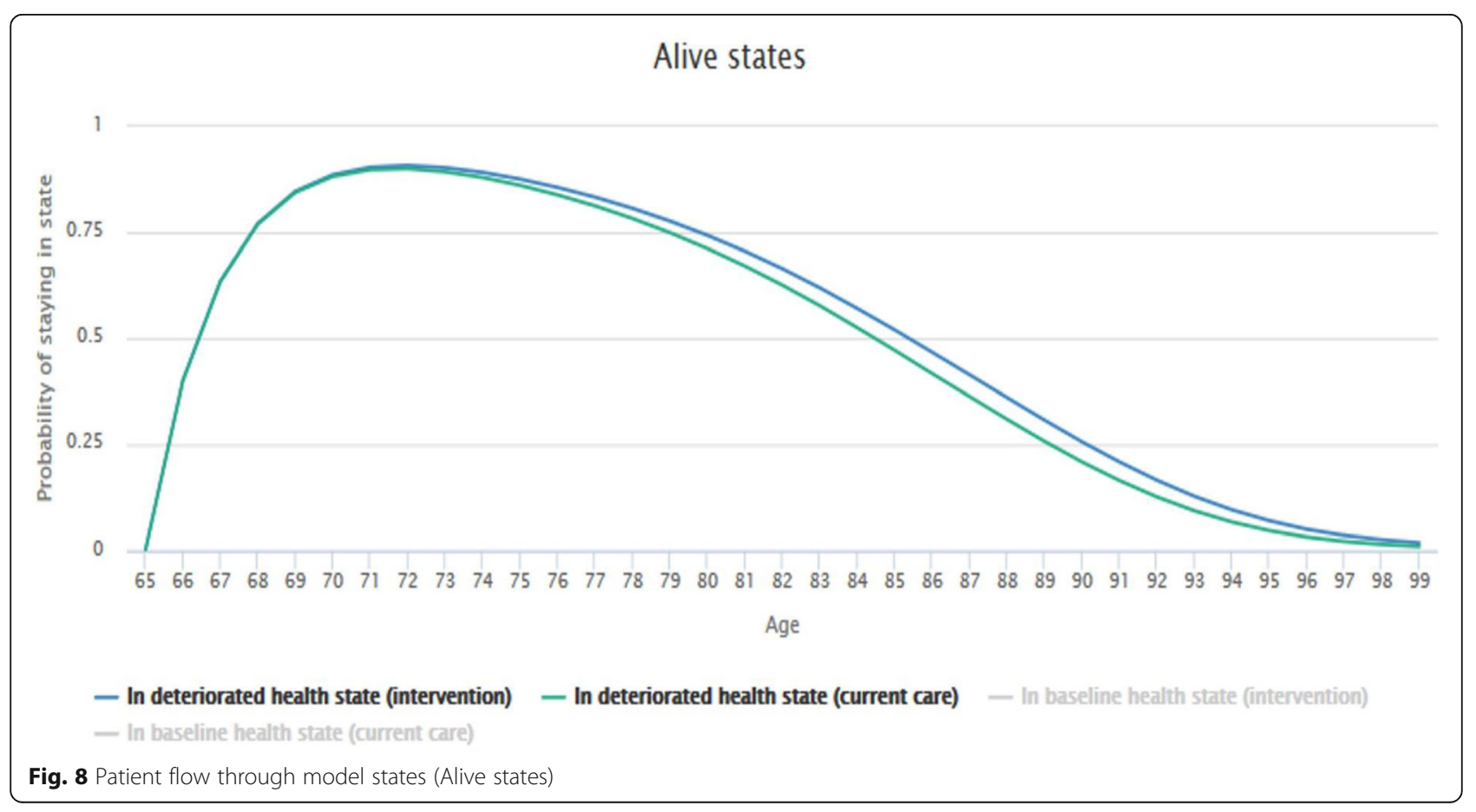




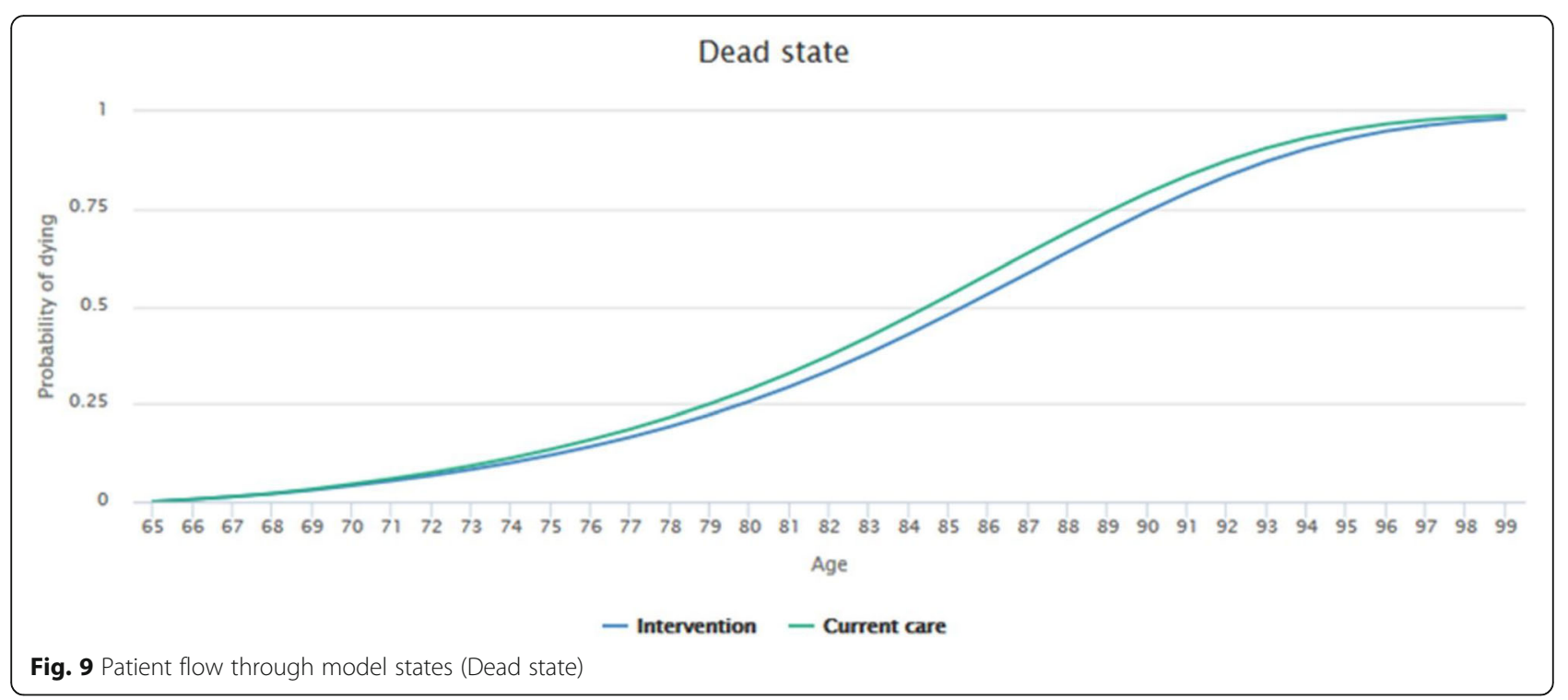

however, it was pointed out that studies with positive economic results were based on a collaborative model, in which all the team members had a defined role, the objectives and guides were shared and an effective communication method was employed.

Specifically, as regards the reduction of psychotropic drugs, it should be noted that at the beginning of the study we verified the prevalence of psychotropic prescriptions and polypharmacy in dementia patients and that it was higher than that described by other authors [38-40]. For this reason, the intervention is probably cost-effective at the time of implementation and after 6 months. The impact of the intervention and its costutility after a longer period and when the prevalence of drugs is lower still must be studied.

This fact might be reflected in the Ballard et al. study [24] in which discontinuance of psychotropic drugs in the study population had a negative impact on patients' quality of life. In the discussion, the authors note that the results must be due to a general reduction in the prescription of psychotropic drugs over the previous 5 years, leading to a low prevalence $(18 \%)$ of psychotropic drugs among the study population. This shows that patients that currently have a psychotropic drug prescribed probably have more severe neuropsychiatric symptoms than in the past.

The results obtained from this cost-utility study cannot be compared to the results of other cost-effectiveness studies due to the different methodologies used and interventions performed [23, 28,41,42], as well as the type of patients included [23] and results analyzed.

As for its limitations of this analysis is the very nature of the study since it is not a clinical trial but a pre/post intervention study. Morover, as a limitation, the progress of patients condition has not been taken into account, in the original article describing the intervention no further clinical evaluations were carried out after the initial patient assessment; but it shows that deprescription decisions taken during the intervention remained in the sample over some months, Another limitation is that the model we use does not match perfectly the baseline health state of CUA model, because there were no patients without dementia, and the probability that patients with dementia would improve and go to the baseline health state was zero. Lastly, common to all cost-utility analyses, is that societal benefits and costs are not taken into account,. Despite these limitations, as for its strengths, this study makes it possible to compare different ICERs of the health interventions and policies.

\section{Conclusion}

The results of this analysis showed that our intervention was dominant, that is, better (more effective) and cheaper than the current (standard) care. This also means that the intervention is always better than the standard care and, therefore, possibly of value to interested decision makers since the prevalence of dementia is on the rise due to an ever-larger aging population. Having demonstrated its cost-effectiveness, the implementation of a guideline for reducing prescriptions based on the consensus of all the professionals involved in patients' care leads to proven benefits for both the patients themselves and the healthcare system.

\section{Abbreviations}

ATC: Anatomical and therapeutic chemical classification system; BPSD: Behavioral and psychological symptoms of dementia; DAM: Decision analytic modeling; GDS: Global dementia scale; GP: General practitioner; HRQoL: Health-related Quality of life; ICER: Incremental cost-effectiveness ratio; MAFEIP: Monitoring and Assessment Framework for the European Innovation Partnership on Active and Healthy Ageing tool; QALYS: Quality adjusted life 
years; RR: Relative risk; WHO: World Health Organization; WTP: Willingness to pay

\section{Acknowledgements}

This study was awarded best poster communication in the European General Practice Research Network (EGPRN) [43] and the Spanish Society of Primary Care Pharmacists (SEFAP) conferences. It also received the VII Chiesi Award for Primary Care Pharmaceutical Research. The authors thank Lluis Segú for his support with eSalut database and Colleen McCarroll for English language support.

\section{Authors' contributions}

MM and GS carried out the study design and supervised the data collection, contributed to the data analysis, data interpretation, discussion and answers to the reviewers. FF and FL collaborated on the analyses, PT-M coordinate the study, contributed to data interpretation, writing of the manuscript, discussion and answers to the reviewers. All authors wrote and reviewed the final version of the paper. All authors have read and approved the final manuscript.

\section{Funding}

No funding was received.

\section{Availability of data and materials}

The datasets generated and/or analyzed in this study are not publicly available due to the policies of our institution but are available upon request from the corresponding author.

\section{Declarations}

\section{Ethics approval and consent to participate}

The study was approved by the Ethics and Clinical Research Committee of the Jordi Gol Primary Care Research Institute (IDIAP, Institut d'Investigació en Atenció Primària Jordi Gol) of the Catalan Health Institute (ICS, Institut Catalò de la Salut, Code: P15/120). This paper shows the modeling and economic evaluation of the data from the previous clinical study [31] and has been carried out following the guidelines and recommendations of good practice in research (https://www.idiapjgol.org/index.php/en/support-tools). The Jordi Gol IDIAP constitutes the ethics committee for all primary care activity within the ICS. .

\section{Consent for publication}

Not applicable.

\section{Competing interests}

All authors declare that they have no conflicts of interest related to this study.

\section{Author details}

'Servei d'Atenció Primària Vallès Occidental, Direcció d'Atenció Primària Metropolitana Nord. Institut Català de la Salut. Sabadell, Barcelona, Spain. ${ }^{2}$ Grup de Recerca Multidisciplinar en Salut i Societat (GREMSAS), accredited by AGAUR (2017 SGR 917), Barcelona, Spain. ${ }^{3}$ Tilburg School of Humanities and Digital Sciences, Tilburg University, Tilburg, The Netherlands. ${ }^{4}$ Open Evidence Research, Universitat Oberta de Catalunya, Barcelona, Spain. ${ }^{5}$ Unitat de Suport a la Recerca Metropolitana Nord, Institut Universitari d'Investigació en Atenció Primària Jordi Gol (IDIAP Jordi Gol), Mataró, Barcelona, Spain. ${ }^{6}$ Department of Information and Communication Sciences, Universitat Oberta de Catalunya, Barcelona, Spain.

Received: 19 January 2021 Accepted: 11 May 2021 Published online: 22 May 2021

\section{References}

1. Scottish Intercollegiate Guideline Network. Management of patients with dementia: A national clinical guideline. Guidel. 2006;86(February):1-55.

2. Ballard C, Lana MM, Theodoulou M, Douglas S, McShane R, Jacoby R, et al. A randomised, blinded, placebo-controlled trial in dementia patients continuing or stopping neuroleptics (the DART-AD trial). PLoS Med. 2008; 5(4):0587-99.
3. Corbett A, Burns A, Ballard C. Don't use antipsychotics routinely to treat agitation and aggression in people with dementia. BMJ. 2014; 349(nov03 1):g6420.

4. Tampi RR, Tampi DJ, Balachandran S, Srinivasan S. Antipsychotic use in dementia: a systematic review of benefits and risks from meta-analyses. Ther Adv Chronic Dis. 2016;7(5):229-45. https://doi.org/10.1177/204062231 6658463.

5. Billioti de Gage S, Begaud B, Bazin F, Verdoux H, Dartigues J-F, Peres K, et al. Benzodiazepine use and risk of dementia: prospective population based study. BMJ. 2012;345(sep27 4):e6231.

6. Coupland C, Dhiman P, Morriss R, Arthur A, Barton G, Hippisley-Cox J. Antidepressant use and risk of adverse outcomes in older people: population based cohort study. BMJ. 2011;343(7819):1-15.

7. Gómez-Pavón J, González García P, Francés Román I, Vidán Astiz M, Gutiérrez Rodríguez J, Jiménez Díaz G, et al. Recomendaciones en la prevención de reacciones adversas a medicamentos en personas mayores con demencia. Rev Esp Geriatr Gerontol. 2010;45(2):89-96. https://doi.org/1 0.1016/j.regg.2009.10.002

8. Lee SWH, Mak VSL, Tang YW. Pharmacist services in nursing homes: A systematic review and meta-analysis. Br J Clin Pharmacol. 2019;85:2668-88 Blackwell Publishing Ltd.

9. Al-Hashar A, Al-Zakwani I, Eriksson T, Sarakbi A, Al-Zadjali B, Al Mubaihsi S, et al. Impact of medication reconciliation and review and counselling, on adverse drug events and healthcare resource use. Int J Clin Pharm. 2018; 40(5):1154-64. https://doi.org/10.1007/s11096-018-0650-8.

10. Alldred DP, Kennedy M-C, Hughes C, Chen TF, Miller P. Interventions to optimise prescribing for older people in care homes. Cochrane Database Syst Rev. 2016. https://doi.org/10.1002/14651858.CD009095 Alldred DP, editor.

11. Hasan SS, Thiruchelvam K, Kow CS, Ghori MU, Babar ZUD. Economic evaluation of pharmacist-led medication reviews in residential aged care facilities. Expert Rev Pharmacoecon Outcomes Res. 2017;17:431-9 Taylor and Francis Ltd.

12. Jódar-Sánchez F, Malet-Larrea A, Martín JJ, García-Mochón L, López del Amo MP, Martínez-Martínez F, et al. Cost-utility analysis of a medication review with follow-up Service for Older Adults with Polypharmacy in community pharmacies in Spain: the conSIGUE program. Pharmacoeconomics. 2015; 33(6):599-610. https://doi.org/10.1007/s40273-015-0270-2.

13. Chia HS, Ho JAH, Lim BD. Pharmacist review and its impact on Singapore nursing homes. Singap Med J. 2015 Sep 1;56(9):493-501. https://doi.org/1 $0.11622 /$ smedj.2015133.

14. Willeboordse F, Schellevis FG, Chau SH, Hugtenburg JG, Elders PJM. The effectiveness of optimised clinical medication reviews for geriatric patients: Opti- med a cluster randomised controlled trial. Fam Pract. 2017;34(4):43745. https://doi.org/10.1093/fampra/cm×007.

15. Rankin A, Cadogan CA, Patterson SM, Kerse N, Cardwell CR, Bradley MC, et al. Interventions to improve the appropriate use of polypharmacy for older people. Cochrane Database Syst Rev. 2018. https://doi.org/10.1002/14 651858.CD008165 Patterson SM, editor.

16. Dawoud DM, Haines A, Wonderling D, Ashe J, Hill J, Varia M, et al. Cost effectiveness of advanced pharmacy services provided in the community and primary care settings: a systematic review. Pharmacoeconomics. 2019; 37:1241-60 Springer International Publishing.

17. Kwak A, Moon YJ, Song YK, Yun HY, Kim K. Economic impact of pharmacistparticipated medication management for elderly patients in nursing homes: a systematic review. Int J Environ Res Public Health. 2019;16:2955 MDPI AG.

18. Fossey J, Ballard C, Juszczak E, James I, Alder N, Jacoby R, et al. Effect of enhanced psychosocial care on antipsychotic use in nursing home residents with severe dementia: cluster randomised trial. Br Med J. 2006; 332(7544):756-8. https://doi.org/10.1136/bmj.38782.575868.7C.

19. Van Der Spek K, Koopmans RTCM, Smalbrugge M, Nelissen-Vrancken MHJMG, Wetzels RB, Smeets CHW, et al. The effect of biannual medication reviews on the appropriateness of psychotropic drug use for neuropsychiatric symptoms in patients with dementia: a randomised controlled trial. Age Ageing. 2018:47(3):430-7. https://doi.org/10.1093/a geing/afy001.

20. Patterson SM, Hughes CM, Crealey G, Cardwell C, Lapane KL. An evaluation of an adapted U.S. model of pharmaceutical care to improve psychoactive prescribing for nursing home residents in Northern Ireland (Fleetwood Northern Ireland study). J Am Geriatr Soc. 2010;58(1):44-53. https://doi.org/1 0.1111/j.1532-5415.2009.02617.x. 
21. Westbury JL, Gee P, Ling T, Brown DT, Franks KH, Bindoff I, et al. RedUSe: reducing antipsychotic and benzodiazepine prescribing in residential aged care facilities. Med J Aust. 2018;208(9):398-403. https://doi.org/10.5694/mja1 7.00857 .

22. Maidment ID, Barton G, Campbell N, Shaw R, Seare N, Fox C, et al. MEDREV (pharmacy-health psychology intervention in people living with dementia with behaviour that challenges): the feasibility of measuring clinical outcomes and costs of the intervention. BMC Health Serv Res. 2020;20(1):1-9.

23. Ballard C, Corbett A, Orrell M, Williams G, Moniz-Cook E, Romeo R, et al. Impact of person-centred care training and person-centred activities on quality of life, agitation, and antipsychotic use in people with dementia living in nursing homes: a cluster-randomised controlled trial. PLoS Med. 2018;15(2):1-18.

24. Ballard C, Orrell M, Sun Y, Moniz-Cook E, Stafford J, Whitaker R, et al. Impact of antipsychotic review and non-pharmacological intervention on healthrelated quality of life in people with dementia living in care homes: WHEL D_a factorial cluster randomised controlled trial. Int J Geriatr Psychiatry. 2017:32(10):1094-103. https://doi.org/10.1002/gps.4572.

25. Richter C, Berg A, Langner H, Meyer G, Köpke S, Balzer K, et al. Effect of person-centred care on antipsychotic drug use in nursing homes (EPCentCare): a cluster-randomised controlled trial. Age Ageing. 2019;48(3): 419-25. https://doi.org/10.1093/ageing/afz016.

26. Harrison SL, Kouladjian O'Donnell L, Bradley CE, Milte R, Dyer SM, Gnanamanickam ES, et al. Associations between the drug burden index, potentially inappropriate medications and quality of life in residential aged care. Drugs Aging. 2018;35(1):83-91. https://doi.org/10.1007/s40266-017-0513-3.

27. Van Leeuwen E, Petrovic M, van Driel ML, De Sutter Al, Vander Stichele R, Declercq $T$, et al. Withdrawal versus continuation of long-term antipsychotic drug use for behavioural and psychological symptoms in older people with dementia. Cochrane Database Syst Rev. 2018. https://doi.org/10.1002/14651 858.CD007726.pub3.

28. Ballard C, Orrell M, Zhong SY, Moniz-Cook E, Stafford J, Whittaker R, et al. Impact of antipsychotic review and nonpharmacological interventionon antipsychotic use, neuropsychiatric symptoms, and mortality in people with dementia living in nursing homes: a factorial cluster-randomized controlled trial by the well-being and health. Am J Psychiatry. 2016;173(3):252-62. https://doi.org/10.1176/appi.ajp.2015.15010130

29. Abadie F, Boehler C, Lluch M, Sabes-Figuera R, Zamora B. Monitoring and assessment framework for the European innovation partnership on active and healthy ageing (MAFEIP). Second update of the process indicators; 2014.

30. Boehler CE, De Graaf G, Steuten L, Yang Y, Abadie F. Development of a web-based tool for the assessment of health and economic outcomes of the European innovation partnership on active and healthy ageing (EIP on AHA). BMC Med Inform Decis Mak. 2015;15(3):1-10.

31. Massot Mesquida M, Tristany Casas M, Franzi Sisó A, García Muñoz I, Hernández Vian Ó, Torán MP. Consensus and evidence-based medication review to optimize and potentially reduce psychotropic drug prescription in institutionalized dementia patients. BMC Geriatr. 2019;19(1):1-9.

32. WHO. No Title [Internet]. 2020. Available from: https://www.whocc.no/atc_ ddd_index/. Accesed May 2021

33. Birov, Strahil, Christianne Lavin, Veli Stroetmann, Ruth Vilar FL-V. MAFEIP User Guide. 2017. Available from: https://tool.mafeip.eu/assets/files/MAFEIP_ User_Guide_v2_Website.pdf. Cited 2020 Nov 24

34. Barcelona: Oblikue. Base de datos de costes sanitarios españoles: eSalud Available from: http://esalud.oblikue.com/. Accesed May 2021.

35. Lopez-Bastida J, Serrano-Aguilar P, Perestelo-Perez L, Oliva-Moreno J. Socialeconomic costs and quality of life of Alzheimer disease in the Canary Islands, Spain. Neurology. 2006;67(12):2186-91. https://doi.org/10.1212/01. wnl.0000249311.80411.93.

36. CDC. Centers for Disease Control and Prevention. Health-Related Quality of Life (HRQOL). 2020. Available from: https://www.cdc.gov/hrqol/index.htm

37. Sicras A, Rejas J, Arco S, Flores E, Ortega G, Esparcia A, et al. Prevalence, resource utilization and costs of vascular dementia compared to Alzheimer's dementia in a population setting. Dement Geriatr Cogn Disord. 2005;19(56):305-15. https://doi.org/10.1159/000084556.

38. Gobert M, D'hoore W. Prevalence of psychotropic drug use in nursing homes for the aged in Quebec and in the French-speaking area of Switzerland. Int J Geriatr Psychiatry. 2005;20(8):712-21. https://doi.org/10.1 002/gps.1349
39. Gustafsson M, Karlsson S, Gustafson Y, Lövheim H. Psychotropic drug use among people with dementia--a six-month follow-up study. BMC Pharmacol Toxicol. 2013;14(1):56. https://doi.org/10.1186/2050-6511-14-56.

40. Azermai M, Elseviers M, Petrovic M, Van Bortel L, Vander SR. Geriatric drug utilisation of psychotropics in Belgian nursing homes. Hum Psychopharmacol. 2011;26(1):12-20. https://doi.org/10.1002/hup.1160.

41. Richter C, Berg A, Langner H, Meyer G, Köpke S, Balzer K, et al. Effect of person-centred care on antipsychotic drug use in nursing homes (EPCentCare): a cluster-randomised controlled trial. Age Ageing. 2019;48(3): 419-25. https://doi.org/10.1093/ageing/afz016.

42. Maidment ID, Barton G, Campbell N, Shaw R, Seare N, Fox C, et al. MEDREV (pharmacy-health psychology intervention in people living with dementia with behaviour that challenges): the feasibility of measuring clinical outcomes and costs of the intervention. BMC Health Serv Res. 2020;20(1):157.

43. Massot M, Tristany M, Franzi A, Garcia I. Reducing the number of antidepressants, antipsychotics and benzodiazepines in nursing home residents with dementia [Poster]. Int Perspect Prim Care Res. 2016; 4788(June):148

\section{Publisher's Note}

Springer Nature remains neutral with regard to jurisdictional claims in published maps and institutional affiliations.
Ready to submit your research? Choose BMC and benefit from:

- fast, convenient online submission

- thorough peer review by experienced researchers in your field

- rapid publication on acceptance

- support for research data, including large and complex data types

- gold Open Access which fosters wider collaboration and increased citations

- maximum visibility for your research: over $100 \mathrm{M}$ website views per year

At BMC, research is always in progress.

Learn more biomedcentral.com/submissions 